\title{
Variant BDNF Val66Met Polymorphism Affects Extinction of Conditioned Aversive Memory
}

\author{
Hui Yu, ${ }^{1 *}$ Yue Wang, ${ }^{1 *}$ Siobhan Pattwell, ${ }^{3,4 *}$ Deqiang Jing, ${ }^{4}$ Ting Liu, ${ }^{1}$ Yun Zhang, ${ }^{2}$ Kevin G. Bath, ${ }^{4}$ Francis S. Lee, ${ }^{4}$ and \\ Zhe-Yu Chen ${ }^{1}$ \\ ${ }^{1}$ Department of Neurobiology, School of Medicine, and ${ }^{2}$ Key Laboratory of Cardiovascular Remodeling and Function Research, Chinese Ministry of \\ Education and Chinese Ministry of Health, Qilu Hospital, Shandong University, Jinan, Shandong 250012, China, and ${ }^{3}$ Graduate Program in Neuroscience \\ and ${ }^{4}$ Department of Psychiatry, Weill Cornell Medical College of Cornell University, New York, New York 10065
}

Brain-derived neurotrophic factor (BDNF) plays important roles in activity-dependent plasticity processes, such as long-term potentiation, learning, and memory. The recently reported human BDNF Val66Met $\left(\mathrm{BDNF}_{\mathrm{Met}}\right)$ polymorphism has been shown to lead to altered hippocampal volume and impaired hippocampal-dependent memory and is associated with a variety of neuropsychiatric disorders. There are few studies, however, that investigate the effect of the $\mathrm{BDNF}_{\mathrm{Met}}$ polymorphism on hippocampal-independent memory processes. A conditioned taste aversion (CTA) task was used for studying the mechanisms of long-term, hippocampal-independent, nondeclarative memory in the mammalian brain. Using the CTA paradigm, we found a novel impairment in extinction learning, but not acquisition or retention, of aversive memories resulting from the variant $B D N F_{M e t} \cdot B D N F_{M e t}$ mice were slower to extinguish an aversive CTA memory compared with wild-type counterparts. Moreover, the $\mathrm{BDNF}_{\mathrm{Met}}$ was associated with smaller volume and decreased neuronal dendritic complexity in the ventromedial prefrontal cortex (vmPFC), which plays a significant role in extinction of CTA. Finally, this delay in extinction learning could be rescued pharmacologically with a cognitive enhancer, D-cycloserine (DCS). To our knowledge, this is the first evidence that the $\mathrm{BDNF}_{\mathrm{Met}}$ polymorphism contributes to abnormalities in memory extinction. This abnormality in extinction learning may be explained by alterations in neuronal morphology, as well as decreased neural activity in the vmPFC. Importantly, DCS was effective in rescuing this delay in extinction, suggesting that when coupled with behavior therapy, DCS may be an effective treatment option for anxiety disorders in humans with this genetic variant BDNF.

\section{Introduction}

Brain-derived neurotrophic factor (BDNF), a molecule known to regulate neuronal survival and differentiation, plays an important role in activity-dependent plasticity processes, such as longterm potentiation (LTP), learning, and memory (Huang and Reichardt, 2001; Chao, 2003). Genetic, as well as pharmacologic, inhibition of BDNF signaling leads to a reduction in LTP, resulting in impairments on several different memory tests, such as Morris water maze, passive avoidance, and fear conditioning (Linnarsson et al., 1997; Mizuno et al., 2000; Liu et al., 2004;

Received Nov. 18, 2008; revised Dec. 22, 2008; accepted Feb. 15, 2009.

This work was supported by National Natural Science Foundation of China (30671050, 30725020, 30700258, and 90713016), National 973 Basic Research Program of China (2009CB941403), National High-Tech Research and Development Program of China (2006AA02A406), Cultivation Fund of the Key Science and Technology Innovation Project from Chinese Ministry of Education (707040), Fok Ying Tong Education Foundation (111044), National Alliance for Research on Schizophrenia and Depression (Z.Y.C.), Irma T. Hirsch/Monique Weill-Caulier Trust (F.S.L.), Sackler Institute (K.G.B., F.S.L.), DeWitt-Wallace Fund of the New York Community Trust (F.S.L.), and National Institutes of Health [MH060478 (K.G.B.), NS052819 (F.S.L.), MH068850 (F.S.L.), and MH079513 (F.S.L.)].

*H.Y., Y.W., and S.P. contributed equally to this work.

The authors declare no competing financial interests.

Correspondence should be addressed to either of the following: Zhe-Yu Chen, Department of Neurobiology, School of Medicine, Shandong University, 44 Wenhua Xi Road, Jinan, Shandong 250012, China, E-mail: zheyuchen@sdu.edu.cn; or Francis S. Lee, Graduate Program in Neuroscience and Department of Psychiatry, Weill Cornell Medical College of Cornell University, 1300 York Avenue, Room LC-903, New York, NY 10065. E-mail: fslee@med.cornell.edu.

DOI:10.1523/JNEUROSCI.5539-08.2009

Copyright $\odot 2009$ Society for Neuroscience $\quad$ 0270-6474/09/294056-09\$15.00/0
Heldt et al., 2007). Recently, a common single nucleotide polymorphism (SNP) in the BDNF gene, resulting in a valine-tomethionine substitution at position 66 in the prodomain (Val66Met), was identified and was shown to influence human hippocampal volume and hippocampal-dependent memory (Egan et al., 2003; Hariri et al., 2003; Bueller et al., 2006). This BDNF SNP $\left(\mathrm{BDNF}_{\mathrm{Met}}\right)$ exists only in humans and has been associated with altered susceptibility to a variety of neuropsychiatric disorders, including anxiety and depression (Momose et al., 2002; Sklar et al., 2002; Ventriglia et al., 2002; Sen et al., 2003). Understanding the memory phenotypes associated with BDN$\mathrm{F}_{\mathrm{Met}}$ along with their detailed molecular, cellular, and anatomical bases will prove useful for prevention and treatment of neuropsychiatric disorders. Given the wide distribution of BDNF in the CNS, it is likely that other brain regions in addition to the hippocampus might also be affected by this $\mathrm{BDNF}_{\mathrm{Met}}$ polymorphism. Indeed, studies have shown decreased gray matter volume in the dorsolateral prefrontal cortex, an area associated with planning and higher-order cognitive functioning, as well as decreased volume in temporal and occipital lobar regions in carriers of the Met allele (Pezawas et al., 2004; Ho et al., 2006). While studies have begun to investigate the effects of $\mathrm{BDNF}_{\mathrm{Met}}$ polymorphism on hippocampal-dependent memory processes, few have looked at the effects on memory systems that are largely hippocampal independent.

Recently, a variant $\mathrm{BDNF}_{\mathrm{Met}}$ knock-in mouse, which repro- 
duces the phenotypic hallmarks of humans with this BDNF SNP, was generated (Chen et al., 2006). In this current study, we used the $\mathrm{BDNF}_{\mathrm{Met}}$ knock-in mice to investigate the effect of the BDN$\mathrm{F}_{\mathrm{Met}}$ polymorphism on hippocampal-independent memory processes. A conditioned taste aversion (CTA) task, which is thoroughly independent of hippocampal and striatal activity, was used (Cui et al., 2005). Anatomical and pharmacological data highlight the involvement of several brain structures (e.g., parabrachial nucleus, amygdala, insular cortex), and cellular processes (e.g., expression of immediate early genes, Ras-MAP kinase signaling pathway, protein synthesis) in CTA learning (Welzl et al., 2001). CTA represents a valuable memory paradigm for studying the phenomena and mechanisms of long-term, nondeclarative memory in the mammalian brain (Rosenblum et al., 1997). The task is highly reproducible and the resulting memory is long lasting, permitting analysis of multiple memory phases, including acquisition, retention, and extinction. Here, the effect of the $\mathrm{BDNF}_{\mathrm{Met}} \mathrm{SNP}$ on CTA memory processes, its potential mechanism, and pharmacological intervention are investigated.

\section{Materials and Methods}

Animals. The Institutional Animal Care and Use Committee approved all animal procedures. To reduce experimental variability, age-matched littermate pairs resulting from heterozygous crossings were used for all experiments. Adult wild-type and littermate $\mathrm{BDNF}^{\mathrm{Met} / \mathrm{Met}}$ male mice (2-3 months old) derived from heterozygous $\mathrm{BDNF}^{+/ \mathrm{Met}} \times \mathrm{BDNF}^{+/ \mathrm{Met}}$ crossed parents were used for all experiments. Adult $\mathrm{BDNF}^{+/-}$male mice (2-3 months old) were generated as previously described (Liebl et al., 1997). All behavioral measurements were performed by raters blind to genotype. All animals were kept on a 12:12 light-dark cycle at $22^{\circ} \mathrm{C}$ with food and water available ad libitum unless noted otherwise. All experimental manipulations were performed during the light-on phase of the cycle in accordance with institutional guidelines.

Unconditioned taste preferences. The ability of mice to discriminate between simple tastes was tested using two-bottle, $2 \mathrm{~d}$ intake tests. Mice were housed in cages in which they had ad libitum access to food, but restricted (from 9:00 to 9:30 A.M.) access to water presented in two bottles. Mice were given one empty tube and one tube containing water. Every $24 \mathrm{~h}$, the tubes were switched to train the mice to drink from either tube position. The body weights of the mice before and after the water restriction were measured. There was no significant effect of the water restriction on mouse body weight. After 1 week, mice were given two tubes: one tube containing one of four taste solutions $(0.5 \%$ sodium saccharin, $75 \mathrm{~mm} \mathrm{NaCl}, 0.02 \%$ quinine sulfate, or $0.01 \mathrm{M} \mathrm{HCl}$ ), and a second tube containing only water. Intake from each tube was recorded on the first day and again on the second day when tube position was switched. All mice were tested with all four taste solutions ( $n=9-10$ for each taste solution).

CTA test. Mice from each genotype were randomly assigned to receive either an unconditioned (saline injection after sodium saccharin presentation, $n=8$ for each genotype) or a conditioned $(0.15 \mathrm{M} \mathrm{LiCl}$ injection after sodium saccharin presentation, $n=10$ for each genotype) treatment. Each day for 1 week before experimental onset, mice were transferred to individual cages in which they had ad libitum access to food, but restricted (from 9:00 to 9:30 A.M.) access to water presented in two bottles. Water intake during the $30 \mathrm{~min}$ drinking interval was recorded separately for each mouse. At the end of a $7 \mathrm{~d}$ adaptation phase, mice reliably consumed $>1 \mathrm{ml}$ of water during the 30 min interval.

On the day of conditioning, mice were allowed to drink only $0.5 \%$ sodium saccharin $(0.5 \% \mathrm{w} / \mathrm{v})$ (Sigma) provided in two bottles during the $30 \mathrm{~min}$ interval. To induce malaise, each mouse in the conditioned group was given an intraperitoneal injection of $\mathrm{LiCl}(0.15 \mathrm{M}, 2 \%$ of body weight, Sigma-Aldrich Chemical Co.) $40 \mathrm{~min}$ after removal of the bottle containing sodium saccharin. After $\mathrm{LiCl}$ injection, the animals were visibly unwell and ceased all activity for the following several hours. Mice in the unconditioned control group were injected with corresponding amounts of saline.
On the test day, two bottles were inserted into each cage simultaneously, one containing water and the other containing sodium saccharin. Placement of saccharin bottles with reference to the water bottles was counterbalanced. Liquid consumption was determined by weighing both bottles before and after drinking. An aversion index (AI) for the sodium saccharin was calculated as follows: AI (as a percentage $)=[$ water intake (in grams) $] /[$ sodium saccharin intake (in grams) + water intake (in grams) ] $\times 100$. On days 1, 3, 7, and 30 after training, the two-bottle choice test was administered to determine the degree of CTA acquisition and retention $(n=10$ for each genotype per each retention test). To determine the degree of CTA extinction, the two-bottle choice test was repeated for 15 consecutive days after conditioning. At the beginning of 16 th day, all mice were given water only for $9 \mathrm{~d}$. On the 25 th day, the two-bottle selective test was repeated to evaluate spontaneous recovery of the extinguished CTA memory.

Pharmacologic treatment. D-Cycloserine (DCS) (Sigma-Aldrich) was freshly dissolved in saline $(0.9 \% \mathrm{w} / \mathrm{v})$ and injected intraperitoneally at a dose of $15.0 \mathrm{mg} / \mathrm{kg}$. Control animals were injected intraperitoneally with corresponding amounts of saline. The drug dose was chosen on the basis of the results of our preliminary tests and other behavioral studies implicating DCS's involvement in extinction facilitation after a single administration (Ledgerwood et al., 2005).

Tissue collection. In addition to the mice used for extinction trials, separate cohorts of mice were deeply anesthetized with pentobarbital sodium (40 mg/kg, intraperitoneally) $90 \mathrm{~min}$ after sodium saccharin (SAC) exposure and perfused transcardially with a solution of $0.9 \%$ saline followed by $4 \%$ paraformaldehyde in $0.1 \mathrm{~m}$ PBS, pH 7.4. Brains were dissected out and postfixed in 4\% paraformaldehyde for $1 \mathrm{~h}$. Brains were then placed in $10 \%$ sucrose-PBS followed by $20 \%$ and $30 \%$ sucrose-PBS, each for $24 \mathrm{~h}$ at $4^{\circ} \mathrm{C}$. Coronal sections were serially cut at $20 \mu \mathrm{m}$ using a freezing microtome. For stereological analysis, $40 \mu \mathrm{m}$ serial coronal sections were cut throughout whole brain using a freezing sliding microtome. One section was taken every third slice and mounted with $0.01 \%$ gelatin immediately.

Immunohistochemistry. Every fourth serially obtained section $(60 \mu \mathrm{m}$ interval) was mounted and processed for c-Fos immunohistochemical staining. Sections were incubated for $20 \mathrm{~min}$ in $0.3 \%$ hydrogen peroxide in absolute methanol to quench endogenous peroxidase, rinsed (three times, PBS), and blocked in 5\% normal goat serum in PBS at room temperature for $1 \mathrm{~h}$. Sections were then incubated with polyclonal antiFos (1:500; Santa Cruz Biotechnology; catalog \#sc253) at $4^{\circ} \mathrm{C}$ for $24 \mathrm{~h}$ followed by biotinylated goat anti-rabbit antibody (Elite kit, Vector Laboratories) incubation. Bound secondary antibody was then amplified with the Vector Elite $\mathrm{ABC}$ kit and visualized by diaminobenzidine reaction.

Microphotographs of c-Fos immunoreactivity were captured by using a Nikon $80 \mathrm{i}$ light microscope equipped with a charge-coupled device (CCD) camera interfaced to a personal computer. c-Fosimmunoreactive nuclei in vmPFC and hippocampus were counted with the aid of NIS-Elements BR image analysis software, and the number of positive nuclei per square millimeter in the vmPFC and hippocampus was calculated for both regions.

Rapid Golgi impregnation. Golgi impregnation of all brains was conducted using FD Rapid GolgiStain Kit from mice that had not undergone any prior behavioral or drug treatments. Golgi-Cox (G-C) solution (mixture of A and B solutions from kit) was mixed a minimum of $12 \mathrm{~h}$ before use and stored in a dark place at room temperature. Care was taken during all steps to ensure that solutions did not come in contact with metal surfaces. Brains were immersed in $\mathrm{G}-\mathrm{C}$ solution for $14 \mathrm{~d}$ at room temperature (the $\mathrm{G}-\mathrm{C}$ mixture was changed after the initial $12 \mathrm{~h}$ of impregnation). Following $14 \mathrm{~d}$ of incubation, brains were transferred to solution C (10 ml/brain), and incubated for $3 \mathrm{~d}$ at $4^{\circ} \mathrm{C}$, again with the solutions having been changed after the initial $12 \mathrm{~h}$. Brains were then embedded in a $3 \%$ agarose solution, blocked, and cut at room temperature on a vibratome (150 $\mu \mathrm{m}$ sections). Serial sections were immediately mounted onto $0.3 \%$ gelatin coated slides. Once on the slides, before complete drying of tissue, sections were brushed with solution $\mathrm{C}$, and allowed to air dry for $48 \mathrm{~h}$. Slides were then immersed in distilled water 
three times for 5 min each and then transferred into a solution of D \& E (Golgi kit) ( $25 \mathrm{ml}$ of D, $25 \mathrm{ml}$ of $\mathrm{E}$, and $150 \mathrm{ml}$ of distilled water) for 5-10 min at $4^{\circ} \mathrm{C}$, and again rinsed three times for $5 \mathrm{~min}$ each in double-distilled water. Slides were then dehydrated with ethanol, cleared with Histoclear (three times for 5 min each), and coverslipped with DPX mounting medium.

Golgi tracing. Slides containing the Golgi impregnated brain sections were coded before quantitative analysis; the code was not broken until the analysis was complete. To be selected for analysis of dendritic arborization, Golgiimpregnated vmPFC neurons needed to satisfy the following criteria: (1) isolated cell body with a clear relationship of the primary dendrite to the soma, (2) presence of untruncated dendrites, (3) consistent and dark impregnation along the extent of all of the dendrites, and (4) relative isolation from neighboring impregnated cells that could interfere with analysis. For each brain, 25 neurons from the vmPFC subregion were selected. Cells were traced under $40 \times$ lens using Neurolucida software. The morphological traits of cells (fractal dimension analysis) were analyzed using Neuroexplorer, and data were processed and statistical analyses were done using Prism 4.0.

Volume estimation. All contouring and measurements were performed on brain sections from mice that had not undergone any prior behavioral or drug treatments by using a Nikon Eclipse 80i microscope attached to an Optronics camera with Microfire software, which was connected to a computer using Stereoinvestigator software (MicroBrightfield). To standardize section positions in different levels, and to facilitate contouring, a reference system-tangential reference point (TRP) system-was designed based on previous methods in rat (Gabbott et al., 2005). Individual sections chosen by systematic random sampling (SRS) were aligned by the tangential reference point (TRP) system and compared with corresponding levels in a mouse brain atlas. The volume of each region was estimated by using the Cavalieri method as previously described (Chen et al., 2006).

Statistical analyses. Data were analyzed with Student's $t$ test or one-way or two-way repeated-measures ANOVA, followed by Fisher's LSD post hoc comparisons, where appropriate. The significance level was set to 0.05 for all statistical analyses, and all values in the text and figures represent means \pm SEM. Data analyses were performed using SPSS statistical program version 10.0 .

\section{Results}

\section{Unconditioned taste preferences}

During the initial two-bottle unconditioned taste preference test, preference of four taste solutions (sweet, salty, bitter, and acidic) over water was measured. $\mathrm{BDNF}^{\mathrm{Met} / \mathrm{Met}}, \mathrm{BDNF}^{+/ \mathrm{Met}}, \mathrm{BDNF}^{+/-}$, and wild-type mice showed similar taste preferences, with no effect of genotype on any taste (Fig. 1). On the second test day, all genotypes preferred the $0.5 \%$ sodium saccharin to water (genotype, $\left.F_{(3,37)}=0.35, p=0.79\right)$ (Fig. $1 A$ ), preferred water slightly to $75 \mathrm{~mm} \mathrm{NaCl}$ (genotype, $F_{(3,37)}=0.99, p=0.43$ ) (Fig. $1 B$ ), and avoided $0.02 \%$ quinine sulfate (genotype, $F_{(3,37)}=0.39, p=0.76$ ) (Fig. $1 C$ ) and $0.01 \mathrm{M} \mathrm{HCl}$ solutions (genotype, $F_{(3,37)}=0.89, p=$ 0.48) (Fig. $1 D$ ). These results suggested that $\mathrm{BDNF}^{\mathrm{Met} / \mathrm{Met}}$, $\mathrm{BDNF}^{+/ \mathrm{Met}}, \mathrm{BDNF}^{+/-}$, and wild-type mice did not differ in their level of preference for $0.5 \%$ sodium saccharin, $75 \mathrm{~mm} \mathrm{NaCl}$, $0.02 \%$ quinine sulfate, and $0.01 \mathrm{M} \mathrm{HCl}$ solutions. In addition, as homozygous $\mathrm{BDNF}^{-1-}$ mice have been previously shown to have lingual taste bud deficits (Nosrat et al., 1997), these taste preference results suggest no significant alterations in taste dis-
B

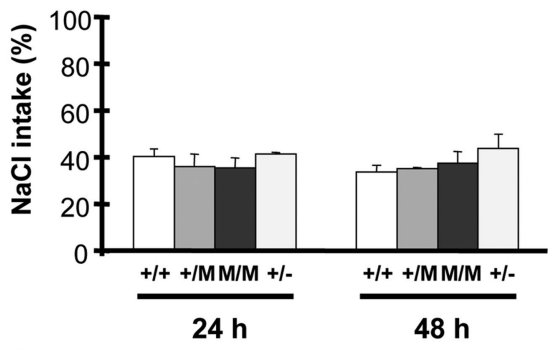

D

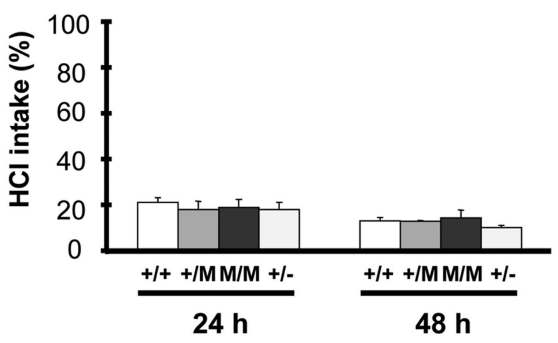

\section{Acquisition of CTA memory}

Mice of all genotypes readily consumed the sodium saccharin solution on the day of conditioning (mean \pm SEM saccharin solution intake: wild type, $1.53 \pm 0.17 \mathrm{ml}$ BDNF $^{+/ M e t}, 1.76 \pm$ $0.23 \mathrm{ml} ; \mathrm{BDNF}^{\mathrm{Met} / \mathrm{Met}}, 2.07 \pm 0.46 \mathrm{ml} ; \mathrm{BDNF}^{+/-}, 2.10 \pm 0.16$ $\mathrm{ml}$; genotype, $\left.F_{(3,71)}=2.20, p=0.15\right)$. Across genotypes, mice that received $\mathrm{LiCl}$ after sodium saccharin exposure (conditioned) developed similar robust levels of aversion to the sodium saccharin solution, relative to unconditioned controls $(p<0.01)$ (Fig. 2) $\left(\mathrm{LiCl}, F_{(1,71)}=262.24, p<0.01\right.$; genotype, $F_{(3,71)}=0.23, p=$ 0.87 ; interaction, $\left.F_{(3,71)}=0.81, p=0.50\right)$. Between-subjects comparisons yielded no significant main effect of genotype (genotype, $F_{(3,39)}=1.61, p=0.23$ ) (Fig. 2).

\section{Retention of CTA memory}

To determine degree of retention for the CTA memory in the $\mathrm{BDNF}_{\mathrm{Met}}$ and BDNF haploinsufficient mice, the aversion index was measured during the CTA test by varying the post- $\mathrm{LiCl}$ injection time interval at which taste aversion was tested (paired with sodium saccharin solution intake) to 3,7 , or $30 \mathrm{~d}$ after conditioning. All mice exhibited a strong preference for regular water, indicating that mice were capable of retaining the CTA memory for at least 1 month. Comparison among the groups revealed no significant differences across genotypes (genotype, $F_{(3,39)}=0.85, p=0.48$ for $30 \mathrm{~d}$ retention test) (Fig. 3 ).

\section{Extinction of CTA memory}

We then determined whether $\mathrm{BDNF}_{\mathrm{Met}}$ and haploinsufficient BDNF mice could extinguish CTA memories. In striking contrast to the memory acquisition behavior, where $\mathrm{BDNF}^{\mathrm{Met} / \mathrm{Met}}$ and $\mathrm{BDNF}^{+/-}$mice readily learned to avoid the solution that was associated with the aversive memory, they failed to show a reduction of this aversion from the fourth day to the 10th day of the experiment, demonstrating impairments in the extinction of the 


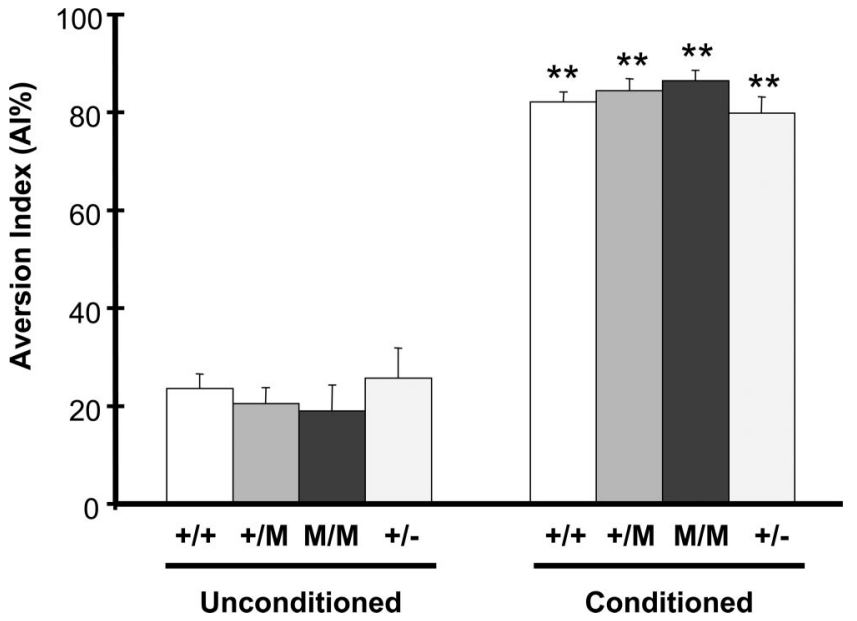

Figure 2. Acquisition of CTA. Mice of all genotypes were injected with LiCl (conditioned) or saline (unconditioned) on conditioning day, and tests were performed $24 \mathrm{~h}$ later. All results are presented as means \pm SEM determined from analysis of $8-10$ mice per genotype, and statistics are in comparison with the unconditioned same-genotype mice $\left({ }^{* *} p<0.01\right)$.

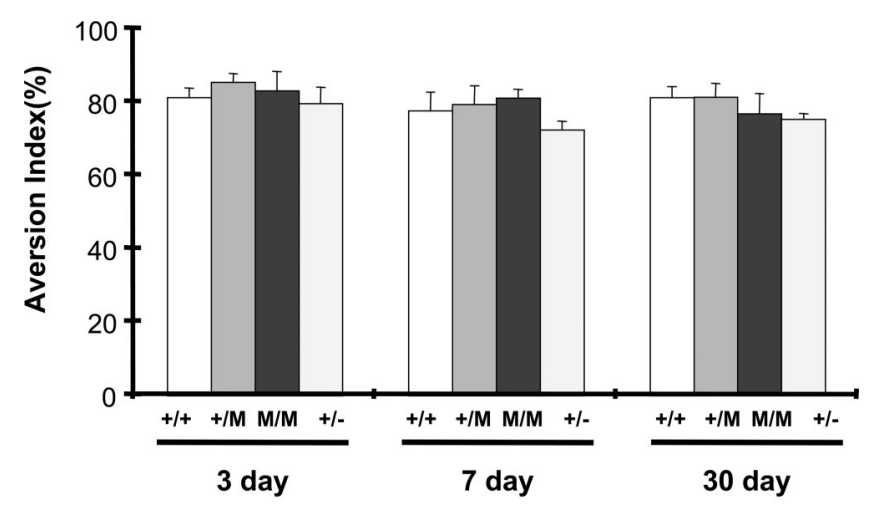

Days since conditioning

Figure 3. Retention of CTA memory. The retention of CTA memory in mice of all genotypes was measured on 3, 7, and $30 \mathrm{~d}$ after conditioning. All results were presented as means \pm SEM determined from analysis of 10 mice per genotype per test day.

aversive memory compared with both conditioned wild-type and conditioned $\mathrm{BDNF}^{+/ \mathrm{Met}}$ mice (Fig. 4A). Post hoc comparisons revealed significant differences between the conditioned BDN$\mathrm{F}^{\mathrm{Met} / \mathrm{Met}}, \mathrm{BDNF}^{+/-}$, and wild-type mice from day 4 to day 10 (Fig. 4) (genotype within conditioned treatment: genotype, $F_{(3,599)}=26.89, p<0.01$; day, $F_{(14,599)}=71.95, p<0.01$; interaction, $\left.F_{(42,599)}=2.62, p<0.01\right)$. No significant differences in the spontaneous recovery of the CTA memory between the genotypes were found (genotype within spontaneous recovery, $F_{(3,119)}$ $=1.1, p=0.35$; day, $F_{(2,119)}=12.22, p<0.01$; interaction, $F_{(6,119)}$ $=0.89, p=0.58)$. In the unconditioned mice, there was no effect of genotype on the aversion index (supplemental Fig. S1, available at www.jneurosci.org as supplemental material) (genotype within unconditioned, $F_{(3,255)}=1.83, p=0.15$; day, $F_{(7,255)}=$ $2.54, p=0.16$; interaction, $\left.F_{(21,255)}=0.49, p=0.98\right)$.

Although the insular cortex and the amygdala are involved in both acquisition and extinction of CTA (Bahar et al., 2003; Eisenberg et al., 2003; Bermúdez-Rattoni, 2004; Belelovsky et al., 2005; Akirav et al., 2006), recent studies reported that the vmPFC plays an important role in CTA extinction. c-Fos protein expression has been shown to be upregulated in the vmPFC 90 min after SAC exposure during CTA extinction tests, while inhibition of protein synthesis in vmPFC has been shown to result in impaired CTA extinction (Mickley et al., 2005). Here, we show that $\mathrm{BDNF}^{\mathrm{Met} / \mathrm{Met}}$ mice demonstrate normal acquisition but delayed extinction of a CTA memory. Thus, to further investigate the potential mechanism of the extinction impairment in $\mathrm{BDNF}^{\text {Met/Met }}$ mice, we used immunohistochemical techniques to measure c-Fos-positive cells in the vmPFC during CTA extinction. First, we determined the c-Fos levels after drinking novel $\mathrm{SAC}$ in unconditioned wild-type, $\mathrm{BDNF}^{\mathrm{Met} / \mathrm{Met}}$, and $\mathrm{BDNF}^{+/-}$ mice. Mice of all three genotypes had equivalent density of c-Fospositive cells in the vmPFC and in the hippocampus (ANOVA, vmPFC: $F_{(2,14)}=0.06, p=0.95$; hippocampus: $F_{(2,14)}=0.40, p=$ 0.68 ) (supplemental Fig. S2, available at www.jneurosci.org as supplemental material). c-Fos levels were assessed in all groups on the fourth day of extinction. The density of c-Fos-positive cells in the vmPFC but not in the hippocampus increased significantly after extinction (vmPFC, extinction: $F_{(1,29)}=897.87, p<0.01$ ) (Fig. $4 B, C$ ). More importantly, wild-type mice showed higher density of c-Fos-positive cells than BDNF $^{\text {Met/Met }}$ and heterozygous BDNF knock-out mice in the vmPFC during extinction (ANOVA, vmPFC: $F_{(2,14)}=225.62, p<0.01$ ) (Fig. $4 C$ ). These results suggest that increased c-Fos expression in the extinction group was attributable to extinction training per se, while the blunted increase in c-Fos-positive cells in $\mathrm{BDNF}^{\mathrm{Met} / \mathrm{Met}}$ and $\mathrm{BDNF}^{+/-}$mice may be an effect of genotype. The c-Fos immunostaining results in the vmPFC are consistent with the behavior results.

\section{Anatomical basis of CTA extinction deficit}

It was then investigated whether there were anatomical abnormalities in the vmPFC, which has been shown to play a significant role in extinction of both CTA and conditioned fear responses (Morgan et al., 1993; Quirk et al., 2000; Milad and Quirk, 2002; Barrett et al., 2003; Santini et al., 2004; Mickley et al., 2005; Milad et al., 2005; Quirk and Mueller, 2008). BDNF ${ }^{\text {Met/Met }}$ and $\mathrm{BDNF}^{+/-}$mice were histologically prepared for stereologic volume estimation of vmPFC from Nissl-stained sections. Using Cavalieri volume estimation, we detected a significant decrease (16.71\% for $\mathrm{BDNF}^{\mathrm{Met} / \mathrm{Met}}$ mice; $17.78 \%$ for $\mathrm{BDNF}^{+/-}$mice) in ventromedial prefrontal cortical volume in $\mathrm{BDNF}^{\mathrm{Met} / \mathrm{Met}}$ and $\mathrm{BDNF}^{+/-}$mice compared with age-matched, littermate wildtype controls (Fig. 5A). We also measured striatal volume, because in human studies this structure has not been reported to be altered by the $\mathrm{BDNF}_{\mathrm{Met}}$ polymorphism (Pezawas et al., 2004), and found no alteration in mouse striatal volumes across genotype (Fig. 5A). Because secreted BDNF regulates neuronal differentiation (Huang and Reichardt, 2001; Chao, 2003), the decreased vmPFC volume may be due to altered neuronal morphology. Golgi staining was used to visualize individual vmPFC neurons in layer $2 / 3$ and to analyze dendritic complexity in $\mathrm{BDNF}^{\mathrm{Met} / \mathrm{Met}}$ as well as in $\mathrm{BDNF}^{+/-}$mice. Fractal dimension analyses was used to quantify how completely a neuron fills its dendritic field (Caserta et al., 1995), and revealed a significant decrease in dendritic arbor complexity in the vmPFC neurons from $\mathrm{BDNF}^{\mathrm{Met} / \mathrm{Met}}$ and $\mathrm{BDNF}^{+/-}$compared with littermate wild-type mice (Fig. $5 B-D$ ). These results suggest that the vmPFC, a brain region that has been shown to play a significant role in mediating extinction behavior, has altered anatomy, as well as altered neuronal morphology in the BDNF ${ }^{\text {Met/Met }}$ mice. 
D-Cycloserine rescue of extinction impairment in CTA memory

In an attempt to rescue the CTA extinction learning delays in $\mathrm{BDNF}^{\mathrm{Met} / \mathrm{Met}}$ and $\mathrm{BDNF}^{+/-}$mice, mice were injected intraperitoneally with either the NMDA receptor partial agonist, DCS (15 mg/kg, i.p.), or vehicle after the third extinction trial. DCS was chosen as acute DCS treatment has been shown to facilitate extinction learning in a variety of paradigms (Davis et al., 2003, 2006; Ledgerwood et al., 2005; Otto et al., 2007), as well as enhance NMDAdependent signaling independent of BDNF. In contrast to our previous CTA extinction findings, which showed genotype effects, no significant genotype effect was observed after DCS administration (Fig. 6A). Aversion index scores from extinction day 4 to day 10 showed no significant difference between genotypes (genotype, $F_{(3,599)}=1.08, p=0.36$; day, $F_{(14,599)}$ $=103.13, p<0.01$; interaction, $F_{(42,599)}=$ $0.46, p=0.10)$, suggesting rescue by DCS of the delayed extinction learning in BDN$\mathrm{F}^{\mathrm{Met} / \mathrm{Met}}$ and $\mathrm{BDNF}^{+/-}$mice. These data revealed that $\mathrm{D}$-cycloserine is able to rescue delayed extinction learning in $\mathrm{BDNF}^{\mathrm{Met} / \mathrm{Met}}$ and $\mathrm{BDNF}^{+/-}$mice. In contrast to DCS treatment, saline injections did not enhance CTA extinction in any of the genotypes under study (Fig. 6A), and a significant effect of genotype on the aversion index across days 4-10 of extinction remained (genotype, $F_{(3,359)}=317.70, p<$ 0.01 ; day, $F_{(14,359)}=60.33, p<0.01$; interaction, $\left.F_{(42,359)}=2.38, p<0.01\right)$. Separate cohorts of mice c-Fos-positive cells were counted on extinction day 4 after DCS or saline treatment and density of c-Fospositive cells in the saline group was similar to that of the extinction group (Figs. $4 B, 6 B)$. All genotypes receiving DCS treatment showed equivalent c-Fos levels (vmPFC: $F_{(2,14)}=2.91, p=0.11$ ) (Fig. 6C). DCS-treated $\mathrm{BDNF}^{\mathrm{Met} / \mathrm{Met}}$ and $\mathrm{BDNF}^{+/-}$mice showed significantly higher density of c-Fos-labeled cells than saline-treated littermates (vmPFC: $F_{(3,19)}$ $=124.49, p<0.01)$.

\section{Discussion}

The goal of this study was to identify novel behavioral phenotypes associated with the human BDNF SNP (Val66Met) using a mouse model system that contains the variant $\mathrm{BDNF}_{\mathrm{Met}}$. Using the CTA paradigm, we provide evidence for a new learn-

ing impairment in the $\mathrm{BDNF}_{\mathrm{Met}}$ mice: delayed extinction of aversive memories. This learning impairment is specific to the extinction process, as no learning delays were observed in acquisition or retention of the aversive memory. In addition, there are no detectable sensory abnormalities produced by BDNF gene

C 0.01 , vs wild-type mice).
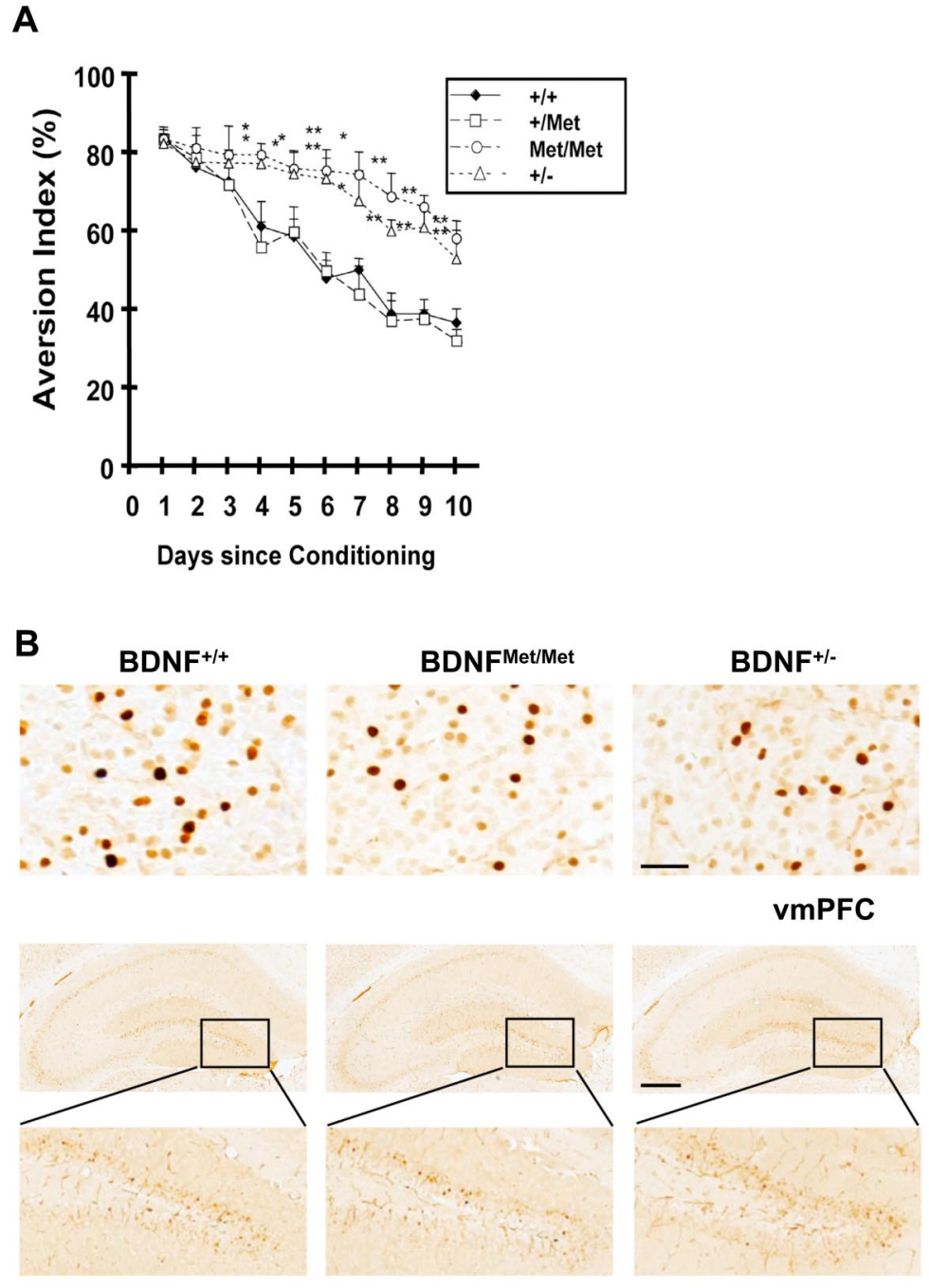

Hippocampus
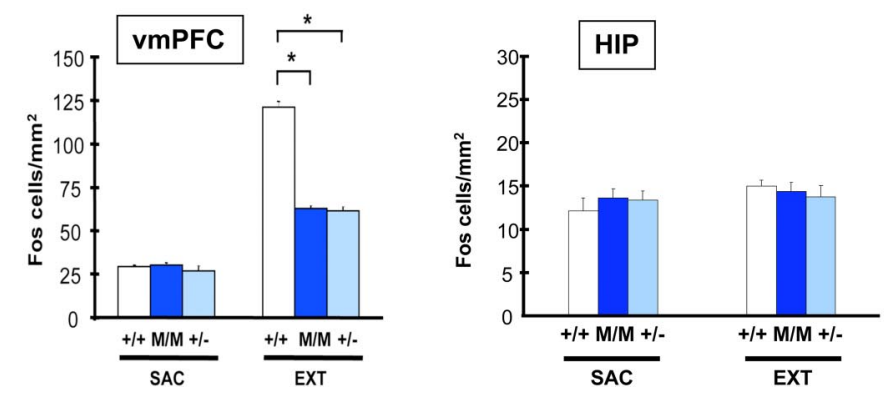

Figure 4. Extinction of CTA memory. $\boldsymbol{A}$, Twenty-four hours after CTA training, extinction tests were performed for 15 consecutive days, and then spontaneous recovery was evaluated as described in Materials and Methods. The aversion indices are presented as means \pm SEM from analysis of 10 mice per genotype $\left({ }^{*} p<0.05\right.$, ${ }^{* *} p<0.01$, vs wild type). $\boldsymbol{B}$, Representative photomicrographs of extinction-induced c-Fos labeling in vmPFC and hippocampus in wild-type, BDNF ${ }^{\mathrm{Met} / \mathrm{Met}}$, and BDNF ${ }^{+/-}$ mice (scale bar in vmPFC, $100 \mu \mathrm{m}$; scale bar in hippocampus, $1000 \mu \mathrm{m}$ ). C, Density of c-Fos-positive cells in vmPFC and hippocampus (HIP) of SAC controls and the extinction (EXT) group are presented as means \pm SEM from five mice per genotype $\left(^{*} p<\right.$

variant that could be responsible for altered CTA extinction learning. Finally, we demonstrate that the delayed extinction learning can be rescued by using a cognitive enhancer, DCS, which acts in a BDNF-independent manner.

Our data provide several new insights into phenotypes associated with the variant $\mathrm{BDNF}_{\mathrm{Met}}$. First, the learning impair- 


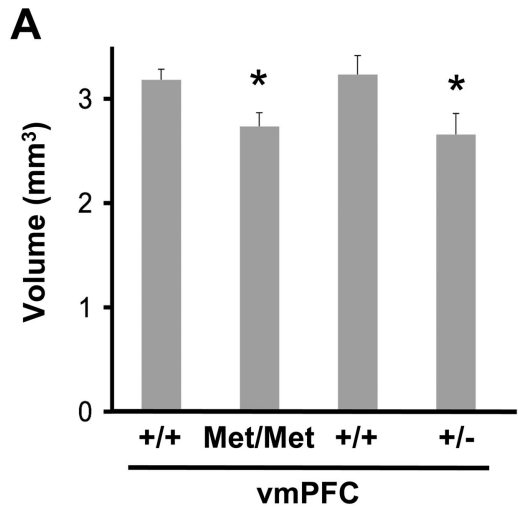

B
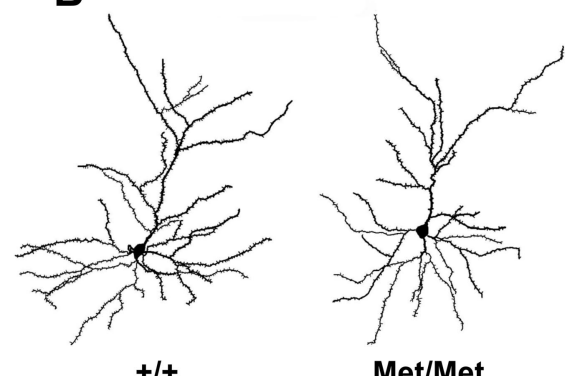

Met/Met

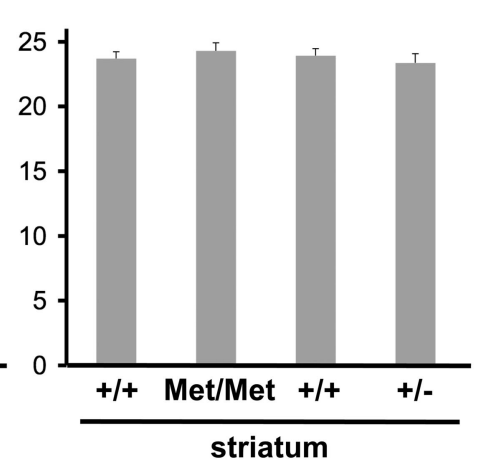

C

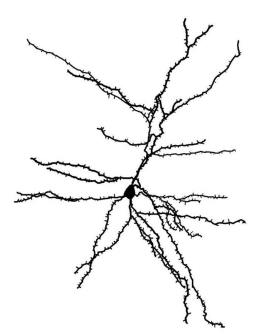

$+/+$

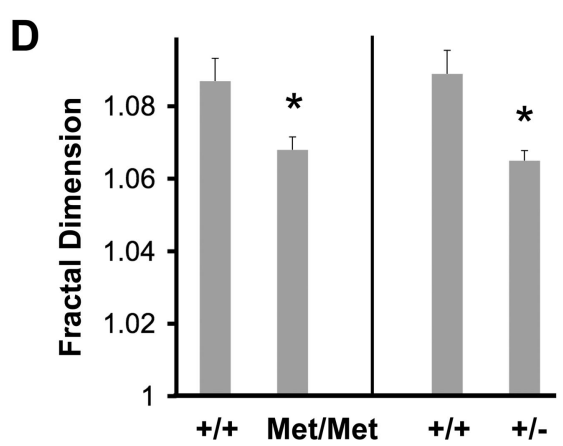

Figure 5. Altered ventromedial prefrontal cortex anatomy in $B D N F^{\text {Met/Met }}$ mice. $\boldsymbol{A}, \mathrm{vmPFC}$ and striatal volume estimations were obtained from Nissl-stained sections from postnatal day 60 (P60) wild-type, BDNF ${ }^{\text {Met/Met }}$, and BDNF ${ }^{+/-}$mice by Cavalieri analyses. All results are presented as means \pm SEM determined from analysis of five mice per genotype ${ }^{*} p<0.05$, Student's $t$ test). $\boldsymbol{B}-\boldsymbol{D}$, Representative examples of Golgi-stained vmPFC pyramidal neurons from P60 BDNF ${ }^{\mathrm{Met} / \mathrm{Met}}(\boldsymbol{B})$ and $\mathrm{BDNF}^{+/-}(\boldsymbol{C})$ mice, and fractal dimension analyses of these Golgi-stained neurons $(\boldsymbol{D})$. All results are presented as means \pm SEM determined from analysis of five mice per genotype, 10 neurons per mouse, and statistics are in comparison with wild-type controls $\left({ }^{*} p<\right.$ 0.01 , Student's $t$ test).

ment in taste aversion is selective only for the extinction process, with no observable impairments in acquisition or retention of CTA in $\mathrm{BDNF}^{\mathrm{Met} / \mathrm{Met}}$ and $\mathrm{BDNF}^{+/-}$mice. In contrast, previous studies have shown BDNF is essential for memory acquisition and retention in hippocampal-dependent tasks. $\mathrm{BDNF}^{+/-}$or hippocampal-specific BDNF deletions block memory acquisition and retention in Morris water maze, radial arm maze, inhibitory avoidance learning, and contextual fear test (Linnarsson et al., 1997; Ma et al., 1998; Mizuno et al., 2000; Liu et al., 2004; Heldt et al., 2007). $\mathrm{BDNF}^{\mathrm{Met} / \mathrm{Met}}$ mice have also been shown to have a deficit in hippocampal-dependent memory acquisition when tested on a contextual fear paradigm (Chen et al., 2006). Although BDNF has also been shown to be involved in amygdaladependent tasks, such as cued fear conditioning, BDNF does not appear to affect memory acquisition or retention in hippocampal-independent nondeclarative CTA memory tests, suggestive of selective roles for BDNF in different learning

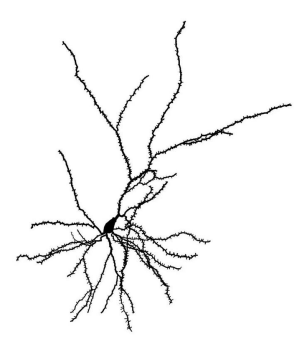

$+/-$ tasks (Rattiner et al., 2004). Before this current study, the BDNF Val66Met polymorphism had not yet been implicated in hippocampal-independent learning tasks. In this context, it is interesting that humans with the $\mathrm{BDNF}_{\text {Met }}$ allele have specific deficits in episodic memory, which is hippocampal dependent, but no deficits in hippocampal-independent processes, such as semantic or working memory (Egan et al., 2003; Hariri et al., 2003).

Second, this is the first study showing an impairment in extinction learning in $\mathrm{BDNF}^{\mathrm{Met} / \mathrm{Met}}$ mice. BDNF has been previously shown to be involved in conditioned fear extinction. Hippocampusspecific deletion of BDNF in adult mice impairs extinction of aversive memories (Heldt et al., 2007), yet an effect of the $\mathrm{BDNF}_{\text {Met }}$ polymorphism on extinction learning has never before been shown. We found that $\mathrm{BDNF}^{\mathrm{Met} / \mathrm{Met}}$ mice and $\mathrm{BDNF}^{+/-}$mice, but not $\mathrm{BDNF}^{+/ \mathrm{Met}}$ mice, are slower to extinguish a learned aversive response compared with wildtype counterparts. Because BDNF ${ }^{\text {Met/Met }}$ and $\mathrm{BDNF}^{+/-}$mice showed similar $\mathrm{AI}$ scores on day 1 of extinction, it is unlikely that they developed a stronger aversion to $\mathrm{LiCl}$ injection. To further confirm that the extinction deficit was not due to the ceiling effects, we altered the $\mathrm{LiCl}$ doses and found that higher concentrations could indeed elicit higher AI scores, suggesting that ceiling effects were not reached with the $0.15 \mathrm{M}$ dose of LiCl (supplemental Fig. S3, available at www.jneurosci.org as supplemental material). Thus, our results further confirm that BDNF is required for the neural plasticity underlying the extinction processes, which is consistent with data obtained from fear conditioning studies (Chhatwal et al., 2006; Bredy et al., 2007; Heldt et al., 2007). In this context, our previous studies have shown that $\mathrm{BDNF}^{\mathrm{Met} / \mathrm{Met}}$ mice displayed increased anxiety-related behaviors in conflict settings (Chen et al., 2006). The inability to properly regulate and inhibit fear responses is a hallmark of most anxiety disorders, such as posttraumatic stress disorder (PTSD) (Myers and Davis, 2002; Davis et al., 2006). Proper regulation of fear learning and extinction has recently been found to be impaired in humans with various genetic polymorphisms (Lonsdorf et al., 2009). Our findings suggest that human carriers with $\mathrm{BDNF}_{\mathrm{Met}}$ allele may have a similar impairment in extinguishing aversive or fearful memories after stressful events, and thus may be at increased risk for developing anxiety disorders, such as PTSD.

The potential mechanism underlying the observed extinction deficit in $\mathrm{BDNF}_{\text {Met }}$ mice was also investigated in our study. Previous studies have highlighted the importance of the ventromedial prefrontal cortex (vmPFC) in the extinction of conditioned emotional responses (Morgan et al., 1993; Quirk 
A
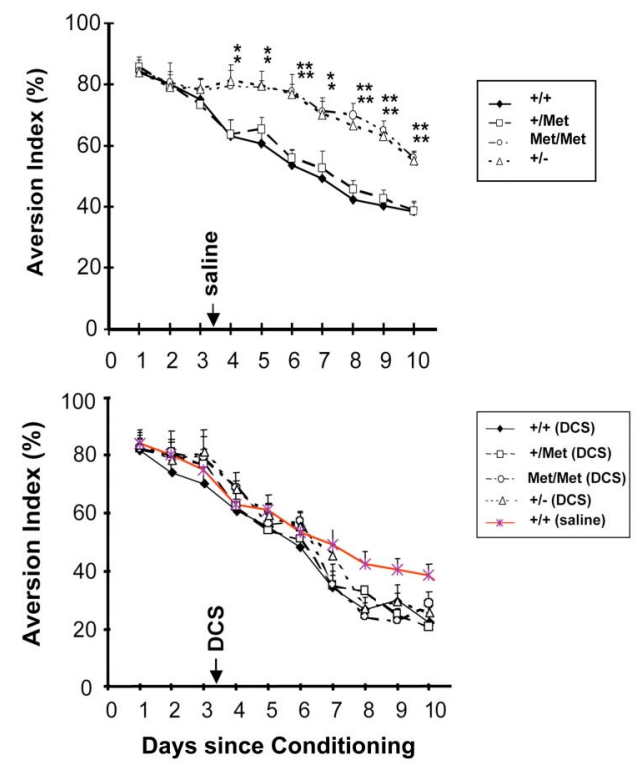

B
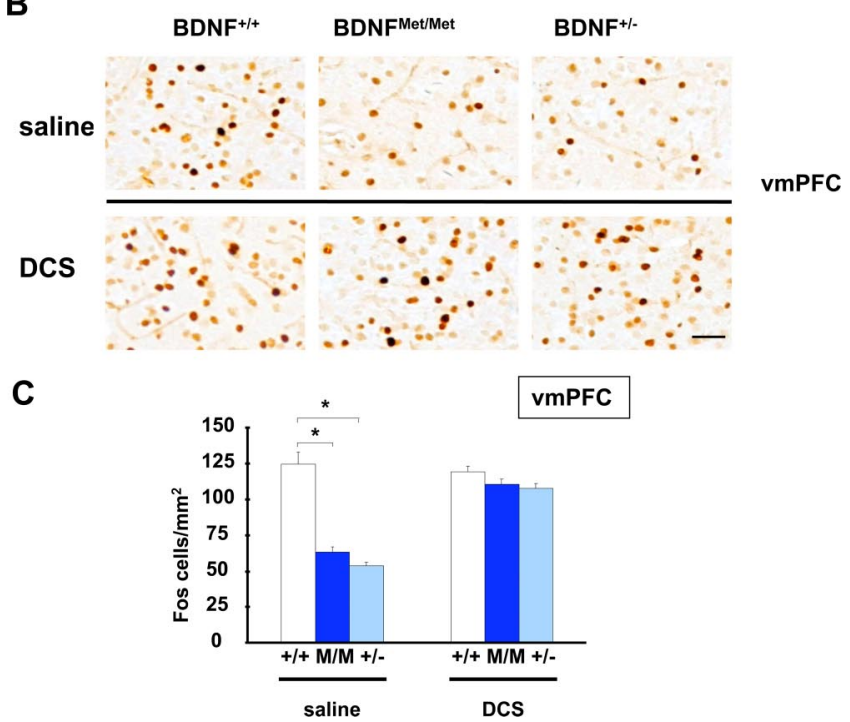

Figure 6. D-Cycloserine rescue of extinction deficit in CTA memory. A, Mice of all genotypes were intraperitoneally injected with either saline or DCS after the third extinction trial (arrow denotes time of injection). The aversion indices are presented as means \pm SEM from analysis of $6-10$ mice per genotype $\left({ }^{*} p<0.05,{ }^{* *} p<0.01\right.$, vs wild type). $\boldsymbol{B}$ Representative photomicrographs of extinction-induced c-Fos labeling in the vmPFC in wild-type, BDNF ${ }^{\text {Met/Met }}$, and BDNF ${ }^{+/-}$mice after saline or DCS treatment (scale bar, 100 $\mu \mathrm{m})$. C, c-Fos-labeled cell density quantitation in the vmPFC after saline or DCS treatment was calculated. The results are presented as means \pm SEM from five mice per genotype $\left({ }^{*} p<0.01\right.$, wild-type mice).

et al., 2000; Milad and Quirk, 2002; Barrett et al., 2003; Santini et al., 2004; Mickley et al., 2005; Milad et al., 2005). Anatomical changes in vmPFC were investigated and revealed that vmPFC volume was significantly decreased in $\mathrm{BDNF}^{\mathrm{Met} / \mathrm{Met}}$ mice compared with wild-type mice. This decrease of vmPFC volume is also consistent with the significant decreases in cortical volume in human carriers of the Met allele (Pezawas et al., 2004). Interestingly, thickness of the vmPFC in humans is also correlated with extinction success in fear conditioning studies (Milad et al., 2005). As evidenced with Golgi staining, the neuronal dendritic complexity among BDNF ${ }^{\text {Met/Met }}$ mice was also significantly decreased compared with wild-type controls (Fig. 5). Thus, the neuroanatomical changes in the BDNF mice may be responsible for the delays in extinction learning. Extinction of previously acquired memories is a new form of learning and a potential target of BDNF-mediated plasticity (Myers and Davis, 2002; Davis et al., 2006). Evidence suggests that the expression of c-Fos (the protein product of the immediate early gene $c$-fos) is a marker of neural activity (Herrera and Robertson, 1996), which can increase dramatically in brain areas mediating extinction learning when animals have extinguished a CTA response (Herry and Mons, 2004; Mickley et al., 2005). Consistent with these findings, we found extinction-induced increases in c-Fos expression in the vmPFC in wild-type mice, yet the number of c-Fos-positive cells in the vmPFC in $\mathrm{BDNF}^{\mathrm{Met} / \mathrm{Met}}$ and $\mathrm{BDNF}^{+/-}$mice was less than in wild-type mice after $4 \mathrm{~d}$ of extinction. When examining the hippocampus as a control region, the number of c-Fos-positive cells was equivalent for all groups. It is widely accepted that neural activity plays a pivotal role in synaptic plasticity. Therefore, the decreased neural activity in vmPFC is consistent with the abnormal CTA extinction observed in BD$\mathrm{NF}^{\mathrm{Met} / \mathrm{Met}}$ and $\mathrm{BDNF}^{+/-}$mice.

Finally, we showed that pharmacological intervention was able to rescue the delay in extinction learning observed in $\mathrm{BDNF}^{\mathrm{Met} / \mathrm{Met}}$ mice. D-Cycloserine, a partial agonist at the glycine recognition site of the glutamatergic NMDA receptor, had been shown to rapidly facilitate extinction learning when administered in single doses before or soon after extinction trials in animals (Davis et al., 2003; Ledgerwood et al., 2005; Davis et al., 2006; Otto et al., 2007). As DCS's onset of action on extinction occurs within $30 \mathrm{~min}$ (Ledgerwood et al., 2005), it precludes any potential mechanisms involving activitydependent increases in BDNF expression. A single administration of DCS was able to facilitate extinction learning and maintain normalized extinction across subsequent trials as NMDA receptor activation has been implicated in long-term extinction memory (Ledgerwood et al., 2003). In addition, in human studies, DCS has been shown to facilitate the extinction of fear in human phobic patients undergoing behavioral exposure therapy (Ressler et al., 2004). In our study, DCS rescued the CTA extinction deficit in $\mathrm{BDNF}^{\mathrm{Met} / \mathrm{Met}}$ mice as well as in $\mathrm{BDNF}^{+/-}$mice (Fig. 6). These findings are the first to demonstrate that a pharmacological agent, acting in a BDNF-independent manner, can reverse a learning deficit in the $\mathrm{BDNF}_{\text {Met }}$ mice.

In conclusion, through the use of a mouse model system, we determined that the variant $\mathrm{BDNF}_{\mathrm{Met}}$ allele leads to a specific impairment in extinction of aversive memory. This abnormality in extinction behavior may be explained by abnormalities observed in vmPFC structures and decreased neural activity. To our knowledge, this is the first evidence that the $\mathrm{BDNF}_{\mathrm{Met}}$ allele contributes to deficits in memory extinction. These findings provide the basis for further studies to determine whether human $\mathrm{BDNF}_{\mathrm{Met}}$ carriers have similar behavioral deficits. In this context, our previous studies have shown that anxiety-related behaviors in $\mathrm{BDNF}^{\mathrm{Met} / \mathrm{Met}}$ mice could not be rescued by the common antidepressant fluoxetine (Chen et al., 2006). In this current study of $\mathrm{BDNF}^{\mathrm{Met} / \mathrm{Met}}$ mice, we found that DCS was effective in rescuing this learning impairment, suggesting that in humans with this genetic variant BDNF, DCS may be an effective treatment option for anxiety disorders when coupled with behavioral exposure therapy, especially under conditions where serotonin reuptake inhibitor antidepressants may be ineffective. In all, our study demonstrates one strategy for how to use model systems of human 
SNPs to identify novel behavioral phenotypes and novel pharmacologic approaches to treat anxiety disorders. Drug discovery strategies based on identifying pharmacological agents that act in a BDNF-independent manner may improve therapeutic responses for humans with this common BDNF polymorphism.

\section{References}

Akirav I, Raizel H, Maroun M (2006) Enhancement of conditioned fear extinction by infusion of the GABA(A) agonist muscimol into the rat prefrontal cortex and amygdala. Eur J Neurosci 23:758-764.

Bahar A, Samuel A, Hazvi S, Dudai Y (2003) The amygdalar circuit that acquires taste aversion memory differs from the circuit that extinguishes it. Eur J Neurosci 17:1527-1530.

Barrett D, Shumake J, Jones D, Gonzalez-Lima F (2003) Metabolic mapping of mouse brain activity after extinction of a conditioned emotional response. J Neurosci 23:5740-5749.

Belelovsky K, Elkobi A, Kaphzan H, Nairn AC, Rosenblum K (2005) A molecular switch for translational control in taste memory consolidation. Eur J Neurosci 22:2560-2568.

Bermúdez-Rattoni F (2004) Molecular mechanisms of taste-recognition memory. Nat Rev Neurosci 5:209-217.

Bredy TW, Wu H, Crego C, Zellhoefer J, Sun YE, Barad M (2007) Histone modifications around individual BDNF gene promoters in prefrontal cortex are associated with extinction of conditioned fear. Learn Mem 14:268-276.

Bueller JA, Aftab M, Sen S, Gomez-Hassan D, Burmeister M, Zubieta JK (2006) BDNF Val66Met allele is associated with reduced hippocampal volume in healthy subjects. Biol Psychiatry 59:812-815.

Caserta F, Eldred WD, Fernandez E, Hausman RE, Stanford LR, Bulderev SV, Schwarzer S, Stanley HE (1995) Determination of fractal dimension of physiologically characterized neurons in two and three dimensions. J Neurosci Methods 56:133-144.

Chao MV (2003) Neurotrophins and their receptors: a convergence point for many signalling pathways. Nat Rev Neurosci 4:299-309.

Chen ZY, Jing D, Bath KG, Ieraci A, Khan T, Siao CJ, Herrera DG, Toth M, Yang C, McEwen BS, Hempstead BL, Lee FS (2006) Genetic variant BDNF (Val66Met) polymorphism alters anxiety-related behavior. Science 314:140-143.

Chhatwal JP, Stanek-Rattiner L, Davis M, Ressler KJ (2006) Amygdala BDNF signaling is required for consolidation but not encoding of extinction. Nat Neurosci 9:870-872.

Cui Z, Lindl KA, Mei B, Zhang S, Tsien JZ (2005) Requirement of NMDA receptor reactivation for consolidation and storage of nondeclarative taste memory revealed by inducible NR1 knockout. Eur J Neurosci 22:755-763.

Davis M, Walker DL, Myers KM (2003) Role of the amygdala in fear extinction measured with potentiated startle. Ann NY Acad Sci 985:218-232.

Davis M, Ressler K, Rothbaum BO, Richardson R (2006) Effects of D-cycloserine on extinction: translation from preclinical to clinical work. Biol Psychiatry 60:369-375.

Egan MF, Kojima M, Callicott JH, Goldberg TE, Kolachana BS, Bertolino A, Zaitsev E, Gold B, Goldman D, Dean M, Lu B, Weinberger DR (2003) The BDNF val66met polymorphism affects activity-dependent secretion of BDNF and human memory and hippocampal function. Cell 112:257-269.

Eisenberg M, Kobilo T, Berman DE, Dudai Y (2003) Stability of retrieved memory: inverse correlation with trace dominance. Science 301:1102-1104.

Gabbott PL, Warner TA, Jays PR, Salway P, Busby SJ (2005) Prefrontal cortex in the rat: projections to subcortical autonomic, motor, and limbic centers. J Comp Neurol 492:145-177.

Hariri AR, Goldberg TE, Mattay VS, Kolachana BS, Callicott JH, Egan MF, Weinberger DR (2003) Brain-derived neurotrophic factor val66met polymorphism affects human memory-related hippocampal activity and predicts memory performance. J Neurosci 23:6690-6694.

Heldt SA, Stanek L, Chhatwal JP, Ressler KJ (2007) Hippocampus-specific deletion of BDNF in adult mice impairs spatial memory and extinction of aversive memories. Mol Psychiatry 12:656-670.

Herrera DG, Robertson HA (1996) Activation of c-fos in the brain. Prog Neurobiol 50:83-107.
Herry C, Mons N (2004) Resistance to extinction is associated with impaired immediate early gene induction in medial prefrontal cortex and amygdala. Eur J Neurosci 20:781-790.

Ho BC, Milev P, O’Leary DS, Librant A, Andreasen NC, Wassink TH (2006) Cognitive and magnetic resonance imaging brain morphometric correlates of brain-derived neurotrophic factor Val66Met gene polymorphism in patients with schizophrenia and healthy volunteers. Arch Gen Psychiatry 63:731-740.

Huang EJ, Reichardt LF (2001) Neurotrophins: roles in neuronal development and function. Annu Rev Neurosci 24:677-736.

Ledgerwood L, Richardson R, Cranney J (2003) Effects of D-cycloserine on conditioned freezing. Behav Neurosci 117:341-349.

Ledgerwood L, Richardson R, Cranney J (2005) D-cycloserine facilitates extinction of learned fear: effects on reacquisition and generalized extinction. Biol Psychiatry 57:841-847.

Liebl DJ, Tessarollo L, Palko ME, Parada LF (1997) Absence of sensory neurons before target innervation in brain-derived neurotrophic factor-, neurotrophin 3-, and TrkC-deficient embryonic mice. J Neurosci 17:9113-9121.

Linnarsson S, Björklund A, Ernfors P (1997) Learning deficit in BDNF mutant mice. Eur J Neurosci 9:2581-2587.

Liu IY, Lyons WE, Mamounas LA, Thompson RF (2004) Brain-derived neurotrophic factor plays a critical role in contextual fear conditioning. J Neurosci 24:7958-7963.

Lonsdorf TB, Weike AI, Nikamo P, Schalling M, Hamm AO, Öhman A (2009) Genetic gating of human fear learning and extinction. Psychol Sci 20:198-206.

Ma YL, Wang HL, Wu HC, Wei CL, Lee EH (1998) Brain-derived neurotrophic factor antisense oligonucleotide impairs memory retention and inhibits long-term potentiation in rats. Neuroscience 82:957-967.

Mickley GA, Kenmuir CL, Yocom AM, Wellman JA, Biada JM (2005) A role for prefrontal cortex in the extinction of a conditioned taste aversion. Brain Res 1051:176-182.

Milad MR, Quirk GJ (2002) Neurons in medial prefrontal cortex signal memory for fear extinction. Nature 420:70-74.

Milad MR, Quinn BT, Pitman RK, Orr SP, Fischl B, Rauch SL (2005) Thickness of ventromedial prefrontal cortex in humans is correlated with extinction memory. Proc Natl Acad Sci U S A 102:10706-10711.

Mizuno M, Yamada K, Olariu A, Nawa H, Nabeshima T (2000) Involvement of brain-derived neurotrophic factor in spatial memory formation and maintenance in a radial arm maze test in rats. J Neurosci 20:7116-7121.

Momose Y, Murata M, Kobayashi K, Tachikawa M, Nakabayashi Y, Kanazawa I, Toda T (2002) Association studies of multiple candidate genes for Parkinson's disease using single nucleotide polymorphisms. Ann Neurol 51:133-136.

Morgan MA, Romanski LM, LeDoux JE (1993) Extinction of emotional learning: contribution of medial prefrontal cortex. Neurosci Lett 163:109-113.

Myers KM, Davis M (2002) Behavioral and neural analysis of extinction. Neuron 36:567-584.

Nosrat CA, Blomlöf J, ElShamy WM, Ernfors P, Olson L (1997) Lingual deficits in BDNF and NT3 mutant mice leading to gustatory and somatosensory disturbances, respectively. Development 124:1333-1342.

Otto MW, Basden SL, Leyro TM, McHugh RK, Hofmann SG (2007) Clinical perspectives on the combination of D-cycloserine and cognitivebehavioral therapy for the treatment of anxiety disorders. CNS Spectr 12:51-56:59-61.

Pezawas L, Verchinski BA, Mattay VS, Callicott JH, Kolachana BS, Straub RE, Egan MF, Meyer-Lindenberg A, Weinberger DR (2004) The brainderived neurotrophic factor val66met polymorphism and variation in human cortical morphology. J Neurosci 24:10099-10102.

Quirk GJ, Mueller D (2008) Neural mechanisms of extinction learning and retrieval. Neuropsychopharmacology 33:56-72.

Quirk GJ, Russo GK, Barron JL, Lebron K (2000) The role of ventromedial prefrontal cortex in the recovery of extinguished fear. J Neurosci 20:6225-6231.

Rattiner LM, Davis M, French CT, Ressler KJ (2004) BDNF and TrkB receptor involvement in amygdala dependent fear conditioning. J Neurosci 24:4796-4806. 
Ressler KJ, Rothbaum BO, Tannenbaum L, Anderson P, Graap K, Zimand E, Hodges L, Davis M (2004) Cognitive enhancers as adjuncts to psychotherapy: use of D-cycloserine in phobic individuals to facilitate extinction of fear. Arch Gen Psychiatry 61:1136-1144.

Rosenblum K, Berman DE, Hazvi S, Lamprecht R, Dudai Y (1997) NMDA receptor and the tyrosine phosphorylation of its $2 \mathrm{~B}$ subunit in taste learning in the rat insular cortex. J Neurosci 17:5129-5135.

Santini E, Ge H, Ren K, Peña de Ortiz S, Quirk GJ (2004) Consolidation of fear extinction requires protein synthesis in the medial prefrontal cortex. J Neurosci 24:5704-5710

Sen S, Nesse RM, Stoltenberg SF, Li S, Gleiberman L, Chakravarti A, Weder AB, Burmeister M (2003) A BDNF coding variant is associated with the
NEO personality inventory domain neuroticism, a risk factor for depression. Neuropsychopharmacology 28:397-401.

Sklar P, Gabriel SB, McInnis MG, Bennett P, Lim YM, Tsan G, Schaffner S, Kirov G, Jones I, Owen M, Craddock N, DePaulo JR, Lander ES (2002) Family-based association study of 76 candidate genes in bipolar disorder: BDNF is a potential risk locus. Brain-derived neutrophic factor. Mol Psychiatry 7:579-593.

Ventriglia M, Bocchio Chiavetto L, Benussi L, Binetti G, Zanetti O, Riva MA, Gennarelli M (2002) Association between the BDNF 196 A/G polymorphism and sporadic Alzheimer's disease. Mol Psychiatry 7:136-137.

Welzl H, D'Adamo P, Lipp HP (2001) Conditioned taste aversion as a learning and memory paradigm. Behav Brain Res 125:205-213. 